\title{
Increased bone mineral density is associated with breastfeeding history in premenopausal Spanish women
}

Maria Luz Canal-Macias, Raul Roncero-Martin, Jose Maria Moran, Jesus Maria Lavado-Garcia, Maria del Carmen Costa-Fernandez, Juan Diego Pedrera-Zamorano

Metabolic Bone Diseases Research Group (GIEMO), University of Extremadura, School of Nursing and Occupational Therapy, Cáceres, Spain

Submitted: 30 April 2012

Accepted: 29 November 2012

Arch Med Sci 2013; 9, 4: 703-708

DOI: 10.5114/aoms.2013.36903

Copyright (c) 2013 Termedia \& Banach
Corresponding author: Juan Diego PedreraZaramorano MD, PhD Facultad de Enfermeria y Terapia Ocupacional Avd. Universidad s/n 10003 Cáceres, Spain Phone: +34 927257450 Fax: +34 927257451 E-mail: jpedrera@unex.es

\begin{abstract}
Introduction: During lactation abundant calcium is lost from the mother as a result of the amount of breast milk produced. Lactation leads to transient fragility, with some women experiencing even fragility fractures, but nearly all of these women subsequently undergo a large increase in bone mineral density (BMD), confirming that the BMD must have declined during lactation but it increases after weaning. We have retrospectively examined the relationship between the duration of breastfeeding and bone properties in Spanish premenopausal healthy women, to identify the site-specific changes in BMD.

Material and methods: Four hundred and thirty-three premenopausal healthy women, 295 with a mean of $7.82 \pm 6.68$ months of exclusive breastfeeding and 138 control women, were studied. We examined total, trabecular and cortical volumetric $B M D\left(\mathrm{mg} / \mathrm{mm}^{3}\right)$ at the distal radius using peripheral quantitative computed tomography. Areal BMD $\left(\mathrm{g} / \mathrm{cm}^{2}\right)$ was measured using dual energy $\mathrm{X}$-ray absorptiometry at the femoral neck, lumbar spine, trochanter and Ward's triangle. Phalangeal bone ultrasound was measured by amplitude-dependent speed of sound.

Results: Areal BMD analysis at L2-L4 revealed significant intergroup differences $(p<0.05)$. There were significant intergroup differences in the volumetric BMD in both total and cortical bone $(p<0.05)$. The observed BMD of breast-feeders was higher than the BMD in non-breast-feeding women. Additionally, the lactation subgroup analysis revealed significant differences in the areal BMD at trochanter and L2-L4 $(p<0.05)$ and in the cortical volumetric BMD $(p<0.05)$. Conclusions: This study adds to the growing evidence that breastfeeding has no deleterious effects and may confer an additional advantage for BMD in premenopausal women.
\end{abstract}

Key words: lactation, dual-energy X-ray absorptiometry, bone mass, ultrasonography.

\section{Introduction}

Many factors influence bone mineral density (BMD). One important determinant of BMD is calcium dynamics. Marked changes in calcium metabolism are reported during lactation, and abundant calcium is lost from the mother as a result of the amount of breast milk produced, diet and the duration of lactation [1-3]. These phenomena suggest that BMD might change during pregnancy and after parturition. Longitudinal and observational studies have addressed the question of whether BMD is affected during lactation and have well established that BMD declines 
5-10\% during lactation [4] with greater losses from trabecular than cortical bone, and greater losses from axial than appendicular sites [5-12]. In fact although lactation leads to transient fragility, with some women experiencing fragility fractures during lactation, nearly all of these women subsequently undergo a large increase in BMD, confirming that the BMD must have declined during lactation and that it increases after weaning [13-15].

Other studies have followed women after weaning to determine how quickly and fully the BMD is recovered, and it appears from the available data that recovery is complete but the speed of recovery may vary by skeletal site [16].

A number of retrospective cohort and ecological studies (none in Spain), like this one, which examine years later whether recalled months of lactation affect BMD at the time of assessment, have been done in premenopausal women, while others have been done in postmenopausal women $[2,17]$. The conclusion from these studies is that a history of lactation, or months of recalled lactation, confers a neutral or beneficial effect on BMD, fractures, or diagnosis of osteoporosis.

Very few studies suggest that lactation confers long-term harm on the skeleton [2, 18], and now it has been well established that parity and lactation are not risk factors for low BMD or osteoporosis in the long term; instead, both may have a protective effect because of the structural rebuilding that occurs after weaning $[2,19]$.

This study retrospectively examined the relationship between the duration of breastfeeding and bone properties in 433 premenopausal Spanish healthy women, 295 with a mean of $7.82 \pm 6.68$ months of exclusive breastfeeding and 138 control women, to identify the site-specific changes in BMD and examine the effects of breastfeeding on BMD.

\section{Material and methods}

The subjects were 433 healthy premenopausal women aged $18-53$ years. Of these subjects, 295 women reported exclusive breastfeeding; it was expressed as the total months of exclusive breastfeeding (giving an infant no food or liquid other than breast milk). Hence, this information repre- sents the cumulative total duration of lactation experienced by the mother throughout her reproductive life. The mean age (SD) of the breastfeeding group was 44.0 (4.7) years, and 138 women were controls (both nulliparous and non-breastfeeders), with a mean age (SD) of 39.9 (8.2) years. Densitometric characteristics of the control group women including the non-breastfeeding women (88 nulliparous women and 50 parity women) are shown in Table I. Because a statistically significant difference in BMD between these two groups was not found, except borderline statistical differences in the trabecular VBMD between nulliparous and parity $(1-3)(p=0.0576)$, it was decided that "this allows us to use this group as a control of nonbreastfeeding women". All of the premenopausal women's histories indicated current and prior menstrual regularity (11-13 cycles/year). Participants were recruited in a clinical convenience sample. All of the subjects were located in the health district of the province of Caceres (Spain) and had visited the hospital's rheumatology department to assess the risk of osteoporotic fracture. Fully informed consent was obtained in accordance with institutional guidelines, and the study was conducted in accordance with the provisions of the Declaration of Helsinki. The Office for Protection against Research Risks of the University of Extremadura approved the study.

Before the candidates were enrolled in the study, a complete medical history was taken and a physical examination was performed. Nutrient intake was quantified using dietary scales, measuring cups and spoons, as we have described elsewhere, based on 7 days of dietary records [20]. In all cases, the calcium level was corrected for proteins. The study subjects were not taking medication and had no diseases, including those associated with abnormalities in mineral metabolism (diabetes mellitus, liver disease, renal osteodystrophy, or parathyroid, thyroid, adrenal, or ovarian disease) that could interfere with calcium metabolism. All subjects led active lives, but none practiced recreational or professional sports. Baseline characteristics included age, height, weight, parity and total lactation period. The total lactation period was recorded after a detailed interview with

Table I. Densitometric characteristics of the control group based on parity

\begin{tabular}{|lccc|}
\hline Variable & Nulliparous $(n=88)$ & Parity $(1-3)(n=50)$ & Significance \\
\cline { 2 - 3 } & Mean \pm SD & Mean \pm SD & 0.08 \\
\hline Ad-SoS $[\mathrm{m} / \mathrm{s}]$ & $2127.920 \pm 51.110$ & $2111.609 \pm 50.238$ & 0.1279 \\
\hline aBMD $(\mathrm{FN})\left[\mathrm{g} / \mathrm{cm}^{2}\right]$ & $0.892 \pm 0.108$ & $0.927 \pm 0.124$ & 0.2483 \\
\hline aBMD $(\mathrm{L} 2-\mathrm{L4})\left[\mathrm{g} / \mathrm{cm}^{2}\right]$ & $1.075 \pm 0.115$ & $1.100 \pm 0.16$ & 0.0808 \\
\hline Total vBMD $\left[\mathrm{mg} / \mathrm{mm}^{3}\right]$ & $350.632 \pm 47.593$ & $367.121 \pm 59.112$ & 0.0576 \\
\hline Trabecular vBMD $\left[\mathrm{mg} / \mathrm{mm}^{3}\right]$ & $178.174 \pm 34.901$ & $191.751 \pm 42.987$ & 0 \\
\hline
\end{tabular}

Intergroup comparisons were made using the Mann-Whitney U-test. SD - standard deviation 
each participant concerning her lactation history.

We examined volumetric BMD at the distal radius using peripheral quantitative computed tomography (pQCT) (XCT 2000, Stratec Medizintechnik, Pforzheim, Germany). Total trabecular volumetric and cortical BMD (vBMD) $\left(\mathrm{mg} / \mathrm{mm}^{3}\right)$ were measured at the distal radius. Areal BMD $\left(\mathrm{g} / \mathrm{cm}^{2}\right)$ (aBMD) was measured using dual energy X-ray absorptiometry (DXA) (XR-800, Norland Medical Systems Inc., Cooper Surgical, EEUU) at the femoral neck (FN), lumbar spine (L2-L4), trochanter (TR) and Ward's triangle (WT). Phalangeal bone ultrasound was measured by amplitude-dependent speed of sound (Ad-SoS) (DBM Sonic 1200, Carpi, Italy).

Our rationale was to ensure the greatest possible homogeneity in identified breastfeeding subgroups. Subgroup determination was based on a clustering approach. Cumulative lactation data were first classified using parallel hierarchical clustering and a k-means model. Based on this model, 4 subgroups were obtained: non-breast-feeders $(n=138)$ and subjects with $1-10$ months $(5.20 \pm 2.58$ months; $n=235), 11-25$ months (16.00 \pm 3.95 months; $n=54)$ and $26-54$ months (37.0 \pm 9.2 months; $n=6)$ of cumulative lactation.

\section{Statistical analysis}

Subgroup comparisons were made using a 1-way ANOVA and Fisher's protected least significant difference (PLSD) with a 95\% confidence level. Intergroup comparisons were made using the MannWhitney $U$-test. Value of $p$ below 0.05 was considered significant. All values were given as mean \pm standard deviation (SD). Odds ratios (OR) for fracture risk and 95\% confidence intervals are presented. The SPSS version 12.0 statistical package was used.

\section{Results}

Table II presents the baseline characteristics and reproductive history, including parity (as the number of times a participant has come to term and delivered a baby) and gravidity (as the number of

Table II. Demographic, dietetic and bone characteristics

\begin{tabular}{|c|c|c|c|c|c|}
\hline \multirow[t]{2}{*}{ Parameter } & \multicolumn{2}{|c|}{$\begin{array}{l}\text { Breast-feeders } \\
\quad(n=295)\end{array}$} & \multicolumn{2}{|c|}{$\begin{array}{l}\text { Non-breast-feeders (mean } \pm \text { SD) } \\
\qquad(n=138)\end{array}$} & \multirow[t]{2}{*}{$\begin{array}{l}\text { Significance } \\
\text { Value of } p\end{array}$} \\
\hline & Mean \pm SD & Range & Mean \pm SD & Range & \\
\hline Age [years] & $44.08 \pm 4.75$ & $30-53$ & $39.92 \pm 8.30$ & $18-53$ & $<0.0001$ \\
\hline Menarche age [years] & $12.64 \pm 1.38$ & $8-18$ & $12.57 \pm 1.35$ & $9-16$ & NS \\
\hline Weight [kg] & $64.98 \pm 9.36$ & $46.4-102.20$ & $63.92 \pm 10.76$ & $41.7-106.90$ & NS \\
\hline Height [m] & $1.59 \pm 0.5$ & $1.43-1.75$ & $1.60 \pm 0.63$ & $1.45-1.77$ & $<0.01$ \\
\hline $\mathrm{BMI}\left[\mathrm{kg} / \mathrm{m}^{2}\right]$ & $25.66 \pm 3.65$ & $18.82-38.70$ & $24.71 \pm 4.01$ & $18.04-42.02$ & $<0.05$ \\
\hline Parity (range) & & $1-4$ & & $0-3$ & $<0.0001$ \\
\hline Gravidity (range) & & $1-7$ & & $0-5$ & $<0.0001$ \\
\hline Ca intake $[\mathrm{mg} /$ day $]$ & $1041.27 \pm 524.25$ & $175-3056$ & $1107.96 \pm 466.35$ & $221-2648$ & NS \\
\hline Protein [g/day] & $89.09 \pm 29.24$ & 38.84-193.85 & $85.96 \pm 23.03$ & $31.31-136.77$ & NS \\
\hline $\mathrm{Ca} / \operatorname{Prot}[\mathrm{mg} / \mathrm{day}]$ & $11.72 \pm 4.81$ & $3.19-33.15$ & $12.96 \pm 4.76$ & $3.66-26.34$ & NS \\
\hline $\mathrm{P}[\mathrm{mg} / \mathrm{day}]$ & $1366.65 \pm 514.19$ & $359-3283$ & $1406 \pm 460.84$ & $436-2780$ & NS \\
\hline $\mathrm{Ca} / \mathrm{P}$ & $0.73 \pm 0.16$ & $0.28-1.07$ & $0.77 \pm 0.16$ & $0.29-1.18$ & NS \\
\hline $\mathrm{kcal} /$ day & $2222.60 \pm 609.19$ & $610.20-4006.50$ & $2215.10 \pm 584.35$ & $928.80-4693.00$ & NS \\
\hline $\mathrm{aBMD}(\mathrm{FN})\left[\mathrm{g} / \mathrm{cm}^{2}\right]$ & $0.909 \pm 0.11$ & $0.681-1.287$ & $0.904 \pm 0.114$ & $0.681-1.185$ & NS \\
\hline $\mathrm{aBMD}(\mathrm{TR})\left[\mathrm{g} / \mathrm{cm}^{2}\right]$ & $0.701 \pm 0.10$ & $0.462-1.084$ & $0.69 \pm 0.106$ & $0.479-1.046$ & NS \\
\hline $\mathrm{aBMD}(\mathrm{WT})\left[\mathrm{g} / \mathrm{cm}^{2}\right]$ & $0.697 \pm 0.117$ & $0.456-1.175$ & $0.713 \pm 0.119$ & $0.485-1.016$ & NS \\
\hline aBMD (L2-L4) [g/cm²] & $1.10 \pm 0.10$ & $0.90-1.49$ & $1.08 \pm 0.11$ & $0.85-1.49$ & $<0.05$ \\
\hline Ad-SoS $[\mathrm{m} / \mathrm{s}]$ & $2122.801 \pm 51.026$ & $1973-2258$ & $2122.321 \pm 51.216$ & $1980-2275$ & NS \\
\hline Trabecular vBMD [mg/mm³] & $182.536 \pm 35.692$ & $82.8-313.1$ & $182.901 \pm 38.306$ & $84.900-351.400$ & NS \\
\hline Total vBMD $\left[\mathrm{mg} / \mathrm{mm}^{3}\right]$ & $360.99 \pm 48.11$ & $217.70-523.10$ & $356.37 \pm 52.27$ & $237.90-560.10$ & $<0.05$ \\
\hline Cortical vBMD [mg/mm³] & $508.46 \pm 70.98$ & $299.20-738.80$ & $493.95 \pm 77.63$ & $310.10-766.50$ & $<0.05$ \\
\hline$T$-score & $-0.395 \pm 0.769$ & & $-0.488 \pm 0.883$ & & 0.2698 \\
\hline Z-score & $-0.222 \pm 0.786$ & & $-0.339 \pm 0.900$ & & 0.1739 \\
\hline
\end{tabular}

Intergroup comparisons were made using the Mann-Whitney U-test. SD - standard deviation, NS - not significant 
A
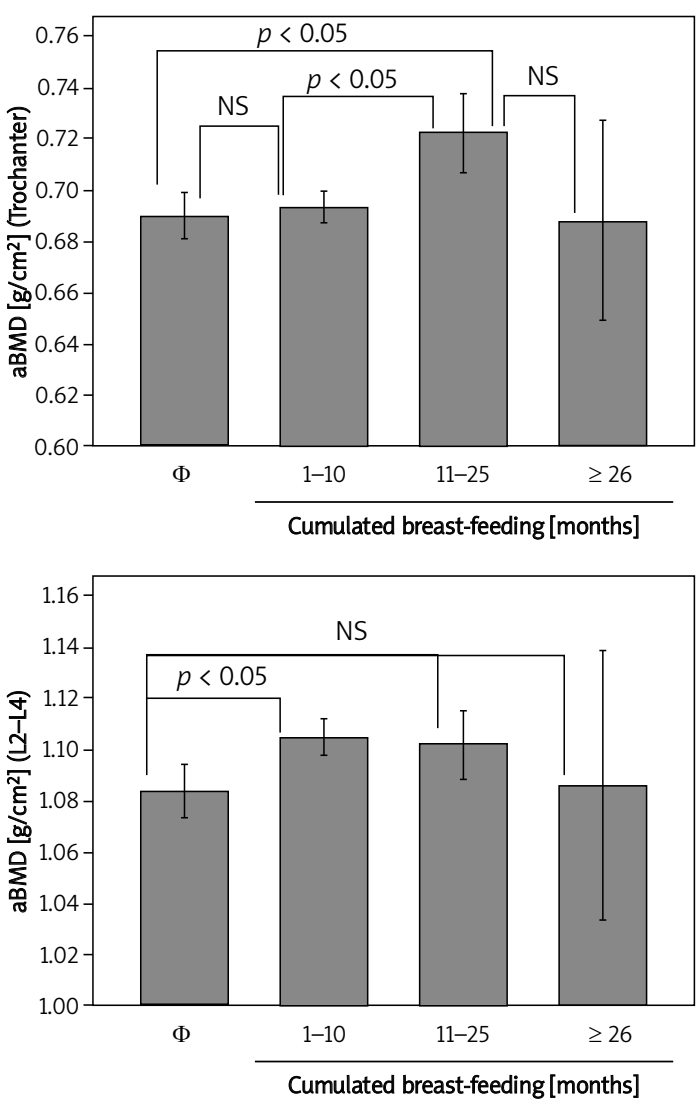

B

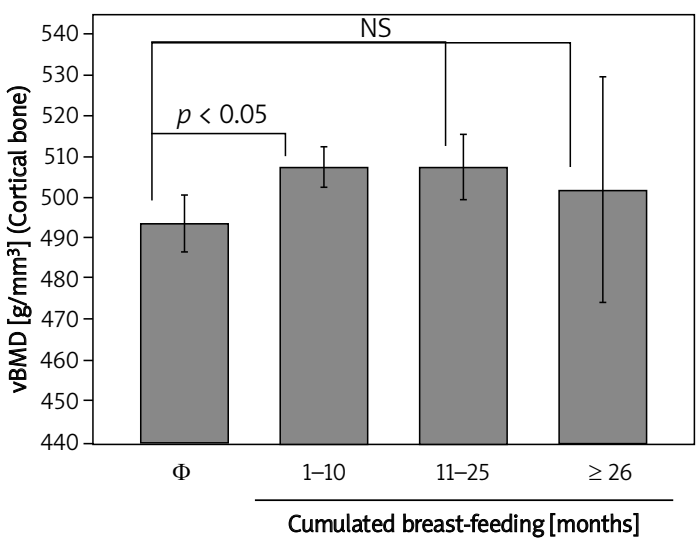

Figure 1. aBMD and $v B M D$ changes in healthy premenopausal women according to cumulative lactation. Subgroup comparisons were made using a 1-way ANOVA and Fisher's PLSD with a 95\% confidence level

$\Phi$ (control women), NS - not significant

times a participant has been pregnant, regardless of whether she gave birth or not), for each group. There were no differences among the two groups in weight or menarcheal age. There were also no differences in the intake of calcium (Ca), protein (Pr), phosphorous (P), kilocalories (Kcal), and $\mathrm{Ca} / \mathrm{Pr}$ and $\mathrm{Ca} / \mathrm{P}$ intergroup ratios. The breastfeeding group had a higher age than the non-breast-feeders ( $p<0.0001)$. Differences were found in parity, gravidity, height and body mass index (BMI). There were no statistically significant differences between breast-feeders and non-breast-feeders for the aBMD values measured at FN, TR and WT and the quantitative bone ultrasound measured at the phalanges ( $p>0.05$ in all) (Table II). Furthermore, there were no intergroup differences in the trabecular vBMD $(p>0.05)$ (Table II). Areal BMD analysis at $L 2-L 4$ revealed significant intergroup differences (Table II). There were also significant intergroup differences in the VBMD in both total and cortical bone (Table II). In both situations, the BMD of women with a lactation history was higher than the BMD in non-breast-feeding women.

The lactation subgroup analysis revealed significant differences in the $\mathrm{ABMD}$ at TR and L2-L4 $(p<0.05)$ and in the cortical vBMD $(p<0.05)$ (Figure 1).

Nine of the participants reported a personal history of fracture ( 2 in the non-breastfeeding group and 7 in the $1-10$ months group) ( $O R=2.0877$ (0.4275-10.1945)). Breast-feeders did not have a history of fracture, which was statistically significantly different $(p=0.7362)$.

\section{Discussion}

This is a retrospective study of the possible association between lactation history and BMD in the long term in Spanish women. We found that premenopausal women with a lactation history had higher BMD at the lumbar spine and higher VBMD, both total and cortical, than non-breast-feeding women. After clustering cumulative lactation, we found differences in the aBMD at the trochanter. Our results are thus confirmatory of much larger epidemiological studies which have examined whether a history of lactation affects BMD or fracture risk later in life, and we obtained similar results [21-23].

Additionally, we observed an increase in the cortical bone measured at the radius. Our results suggest that the effect of lactation on BMD may vary from site to site, confirming that in the long term the recovery is complete, but the speed of recovery may vary by skeletal site.

Age is an important determinant of BMD. Age adjustment is necessary to investigate the relationship between lactation and BMD [24]. Surprisingly, the mean age in the breast-feeding group was significantly higher than the mean age in the nonbreast-feeding group. Thus, although it is possible that the effect of lactation on BMD might be masked by more pronounced determinants of BMD, such as age or diet, we observed a significant difference between groups, confirming that the skeleton becomes stronger afterwards. 
Unfortunately, we had only dietary data at the time of the study, and we found no changes between groups. However, it is possible that subjects' diets had changed between pregnancy and lactation.

Thus, the finding that there were significant differences in BMD between women with a lactation history and the control group may be explained by the following factors.

First, decreased BMD during lactation returns to almost normal and is completely restored in the medium to long term $[25,26]$. Second, many factors affect BMD, but these factors do not always have a general influence on BMD throughout all stages of the life cycle. The lactation period is shorter than a woman's life span. Third, the mobilization of skeletal calcium reserves required to provide calcium to milk are expected to be more from trabecular than cortical bone [25]. Since lactating women should lose from both trabecular and cortical sites while nulliparous or bottle feeding women do not (at least to a similar extent), the higher BMD after lactation observed might mean that more bone was formed after lactation than what was lost during it.

The following have been identified as limitations of this study. We consider that the effect of a lactation history on BMD may be masked by more pronounced determinants of BMD, such as aging, change in diet, change in body size, change in physical activity and other factors. This possibility must be emphasized. Some factors associated with shortterm breast feeding, formula-feeding or nulliparity may also be related to BMD. These factors may include ovarian dysfunction resulting in infertility, malnutrition associated with poor milk secretion and smoking resulting in poor milk secretion. We also did not record the age of first pregnancy, number of years since last breastfeeding or the length of time between pregnancies (and breastfeeding). Unfortunately, we could not investigate these histories in the enrolled subjects. We did not examine lactation as we performed the study in the postweaning period. Our study is retrospective and subject to recall bias so we do not have a way to determine how accurate the recalled duration of breastfeeding was.

In conclusion, our study adds to the growing evidence that breastfeeding has no deleterious effects and may confer an additional advantage for BMD in premenopausal women. Further research is required to determine whether lactation is associated with increases in BMD, particularly at the lumbar spine and cortical bone, and to determine why women differ in their skeletal response to lactation.

\section{References}

1. Kovacs CS. Calcium and bone metabolism disorders during pregnancy and lactation. Endocrinol Metab Clin North Am 2011; 40: 795-826.
2. Bjornerem A, Ahmed LA, Jorgensen L, Stormer J, Joakimsen RM. Breastfeeding protects against hip fracture in postmenopausal women: the Tromso study. J Bone Miner Res 2011; 26: 2843-50.

3. Moller UK, Viõ Streym S, Mosekilde L, Rejnmark L. Changes in bone mineral density and body composition during pregnancy and postpartum. A controlled cohort study. Osteoporos Int 2012; 23: 1213-23.

4. Kovacs CS. Calcium and bone metabolism during pregnancy and lactation. J Mammary Gland Biol Neoplasia 2005; 10: 105-18.

5. Laskey MA, Price RI, Khoo BC, Prentice A. Proximal femur structural geometry changes during and following lactation. Bone 2011; 48: 755-9.

6. Glerean M, Furci A, Galich AM, Fama B, Plantalech L Bone and mineral metabolism in primiparous women and its relationship with breastfeeding: a longitudinal study. Medicina (B Aires) 2010; 70: 227-32.

7. Hellmeyer L, Ossendorf A, Ziller V, Tekesin I, Schmidt S, Hadji P. Quantitative ultrasonometry of the phalanges during pregnancy: a longitudinal study. Climacteric 2006; 9: 446-51.

8. Chan SM, Nelson EA, Leung SS, Cheng JC. Bone mineral density and calcium metabolism of Hong Kong Chinese postpartum women: a 1-y longitudinal study. Eur J Clin Nutr 2005; 59: 868-76.

9. Pluskiewicz W, Drozdzowska B. Bone status after pregnancy and during lactation. Osteoporos Int 2002; 13: 683.

10. Matsushita H, Kurabayashi T, Tomita M, Honda A, Takakuwa K, Tanaka K. The effect of multiple pregnancies on lumbar bone mineral density in Japanese women. Calcif Tissue Int 2002; 71: 10-3.

11. Honda A, Kurabayashi T, Yahata T, Tomita M, Takakuwa K, Tanaka K. Lumbar bone mineral density changes during pregnancy and lactation. Int J Gynaecol Obstet 1998; 63: 253-8.

12. Kurl S, Heinonen K, Jurvelin JS, Lansimies E. Lumbar bone mineral content and density measured using a Lunar DPX densitometer in healthy full-term infants during the first year of life. Clin Physiol Funct Imaging 2002; 22: 222-5.

13. Bezerra FF, Mendonca LM, Lobato EC, O'Brien KO, Donangelo $\mathrm{CM}$. Bone mass is recovered from lactation to postweaning in adolescent mothers with low calcium intakes. Am J Clin Nutr 2004; 80: 1322-6.

14. Ensom MH, Liu PY, Stephenson MD. Effect of pregnancy on bone mineral density in healthy women. Obstet Gynecol Surv 2002; 57: 99-111.

15. Paton LM, Alexander JL, Nowson CA, et al. Pregnancy and lactation have no long-term deleterious effect on measures of bone mineral in healthy women: a twin study. Am J Clin Nutr 2003; 77: 707-14.

16. Akesson A, Vahter M, Berglund M, Eklof T, Bremme K, Bjellerup P. Bone turnover from early pregnancy to postweaning. Acta Obstet Gynecol Scand 2004; 83: 1049-55.

17. Yazici S, Korkmaz $U$, Erkan $M$, et al. The effect of breastfeeding duration on bone mineral density in postmenopausal Turkish women: a population-based study. Arch Med Sci 2011; 7: 486-92.

18. Lissner L, Bengtsson C, Hansson T. Bone mineral content in relation to lactation history in pre- and postmenopausal women. Calcif Tissue Int 1991; 48: 319-25.

19. Melton LJ III, Bryant SC, Wahner HW, et al. Influence of breastfeeding and other reproductive factors on bone mass later in life. Osteoporos Int 1993; 3: 76-83. 
20. Pedrera-Zamorano JD, Lavado-Garcia JM, Roncero-Martin R, Calderon-Garcia JF, Rodriguez-Dominguez T, CanalMacias ML. Effect of beer drinking on ultrasound bone mass in women. Nutrition 2009; 25: 1057-63.

21. Wiklund PK, Xu L, Wang Q, et al. Lactation is associated with greater maternal bone size and bone strength later in life. Osteoporos Int 2012; 23: 1939-45.

22. Karlsson C, Obrant KJ, Karlsson M. Pregnancy and lactation confer reversible bone loss in humans. Osteoporos Int 2001; 12: 828-34.

23. Michaelsson K, Baron JA, Farahmand BY, Ljunghall S. Influence of parity and lactation on hip fracture risk. Am J Epidemiol 2001; 153: 1166-72.

24. Kojima N, Douchi T, Kosha S, Nagata Y. Cross-sectional study of the effects of parturition and lactation on bone mineral density later in life. Maturitas 2002; 41: 203-9.

25. More C, Bhattoa HP, Bettembuk P, Balogh A. The effects of pregnancy and lactation on hormonal status and biochemical markers of bone turnover. Eur J Obstet Gynecol Reprod Biol 2003; 106: 209-13.

26. Affinito P, Tommaselli GA, di CC, Guida F, Nappi C. Changes in bone mineral density and calcium metabolism in breastfeeding women: a one year follow-up study. J Clin Endocrinol Metab 1996; 81: 2314-8. 